\title{
A INDISSOCIABILIDADE TEORIA E PRÁTICA NA GESTÃO DEMOCRÁTICA EM ALAGOAS: UMA ANÁLISE DOS PLANOS DE AÇÃO DO CURSO DE EXTENSÃO EM CONSELHOS ESCOLARES
}

http://dx.doi.org/10.5902/2318133820008

\author{
Javan Sami Araújo dos Santos \\ Edna Cristina do Prado \\ Salatiel Braga Trajano Júnior \\ Universidade Federal de Alagoas, Brasil.
}

\begin{abstract}
Resumo
Neste texto tem-se como objetivo de relatar sobre a importância dos planos de ação do curso de extensão em conselhos escolares como mecanismos de fortalecimento de uma gestão escolar mais participativa no Estado de Alagoas. Para tanto, organizou-se o texto, além da introdução e considerações finais, em três partes. Na primeira há uma reflexão sobre os objetivos e estrutura do curso. Na segunda um panorama da educação alagoana e sua relação com a oferta do curso. As principais características do processo de elaboração e implantação dos trabalhos finais são apresentados na terceira parte. Para a sua redação foram usados depoimentos e dados da coordenação do curso e dos projetos de intervenção propostos por estudantes do curso.

Palavras-chave: gestão democrática, conselho escolar, plano de ação em curso de formação.

\section{THE INSEPARABILITY THEORY AND PRACTICE IN THE MANAGEMENT \\ IN DEMOCRATIC ALAGOAS: AN ANALYSIS OF PLANS FOR \\ EXTENSION COURSE OF ACTION IN SCHOOL BOARDS}

\begin{abstract}
This text has as objective to report on the importance of the extension course of action plans for school boards as strengthening of mechanisms for a more participatory school management in the State of Alagoas. For that it is organized, and the introduction and concluding remarks in three parts. At first there is a reflection on the objectives and structure of the course. The second an overview of Alagoas education and its relationship to offer the course. The main features of the process of elaboration and implementation of the final works are presented in the third part. For their essay were used testimonials and data from the course coordinator and intervention projects proposed by students of the course.

Keywords: democratic management, school board, action plan training course.
\end{abstract}




\section{Introdução}

presente texto tem o objetivo de refletir sobre as contribuições do trabalho final do Curso de Extensão a Distância Formação Continuada em Conselhos Escolares, uma das ações do Programa Nacional de Fortalecimento dos Conselhos Escolares, criado pelo governo federal em 2005 para a gestão democrática nas escolas públicas alagoanas. Para tanto apresenta não apenas os obstáculos institucionais que envolveram a realização de um curso de extensão a distância em um Estado com inúmeras carências, mas, ao mesmo tempo, busca explicitar sua relevância social e pedagógica para a melhoria da educação pública no Estado, em especial, a partir dos planos de ação idealizados e implementados pelos cursistas.

O Curso de Formação Continuada em Conselhos Escolares foi um curso de extensão universitária e teve como objetivo capacitar secretários, dirigentes e técnicos das secretarias municipais e estadual em Alagoas. $\mathrm{O}$ curso foi totalmente à distância e no ambiente virtual de aprendizagem da Universidade Federal de Alagoas.

Sabe-se que após a LDB, lei n. 9.394/96, diversas secretarias de educação dos diferentes Estados e municípios adotaram a política de gestão democrática com vistas à melhorar a qualidade do ensino e de promover a participação dos sujeitos inseridos no ambiente escolar em um trabalho coletivo. Assim, no decorrer do curso estimulou-se que os alunos tomassem suas práticas como objeto do pensamento desse percurso na formação continuada e problematizassem as práticas dos conselheiros nos municípios para que pudessem compreender melhor suas atuações de forma consciente.

O curso ofereceu conteúdos que nutriram as ações no fortalecimento do conselho escolar e dos conselheiros. Contribuímos também com o entendimento de que o conselho escolar é, antes de tudo, um mecanismo de gestão da escola constituído de pessoas que possuem capacidade de participação na melhoria da escola pública.

\section{O curso de extensão a distância formação continuada em conselhos escolares}

O Curso de Extensão a Distância Formação Continuada em Conselhos Escolares é uma das ações do Programa Nacional de Fortalecimento dos Conselhos Escolares, criado pelo governo federal em 2005. O referido programa é composto por, além desta ação à distâncias por técnicos de secretarias de educação, de outras linhas de atuação: Oficinas de Elaboração de Projetos para Implantação e Fortalecimento de Conselhos Escolares, Encontros Municipais de Formação de Conselheiros Escolares e Curso de Formação para Conselheiros Escolares.

O Curso de Extensão a Distância Formação Continuada em Conselhos Escolares é resultado da parceria entre a Secretaria de Educação Básica do Ministério da Educação, universidades federais, União de Dirigentes Municipais de Educação - Undime - e secretarias de educação, estadual e municipais, as quais, por meio Plano de Ações Articuladas, via Sistema Integrado de Monitoramento Execução e Controle, declaram interesse no curso juntamente com a demanda.

$\mathrm{Na}$ relação de parceira cabe ao MEC o pagamento de bolsas, disponibilização do material didático e coordenação geral, à Undime e secretarias a divulgação junto às escolas e à universidade, em âmbito estadual, a oferta do curso a partir da definição das equipes técnica e administrativa, seleção de professores formadores, supervisores e dos 
cursistas, os quais são selecionados entre os técnicos das secretarias de educação que, preferencialmente, trabalharem com a gestão e acompanhamento dos conselhos escolares.

O objetivo do curso é

apoiar os profissionais que atuam nas secretarias de educação contribuindo para a compreensão dos princípios legais que tratam da gestão democrática, em especial, os que versam sobre a escola e a participação das comunidades escolar e local em conselhos escolares, estimulando o desenvolvimento de ações que serão implementadas no âmbito dos sistemas de ensino. (Brasil, 2005, p. 1)

A carga horária do curso corresponde a duzentas horas na modalidade a distância, divididas em duas fases de cem horas, em um período aproximado de seis meses para cada. Na primeira fase são trabalhados os conteúdos apresentados nos seis primeiros cadernos que compõem o material pedagógico do Programa e, na segunda, os demais, totalizando doze cadernos. Cumpre ressaltar que a participação na segunda fase pressupõe a aprovação na etapa anterior. Nas duas fases o último mês é destinado à elaboração de planos de ação e da condição de reavaliação dos cursistas, quando for necessária.

\section{Aspectos da realidade escolar em Alagoas e a atuação do conselho escolar pela melhoria da qualidade educacional}

Alagoas é um Estado com proporções territoriais pequenas, mas, com grandes problemas em diversos âmbitos sociais. De acordo com o Programa das Nações Unidas para o Desenvolvimento, Alagoas possui o mais baixo Índice de Desenvolvimento Humano Municipal do país, com uma nota de 0,631 em uma escala de 0 a 1.

De acordo com a síntese de indicadores 2011 da Pesquisa Nacional por Amostra de Domicílios - Pnad -, Alagoas é o Estado com o maior número de analfabetos do país: $21,8 \%$ de seus habitantes com 15 anos ou mais não sabem saber ler nem escrever.

No Programa Internacional de Avaliação de Alunos - Pisa -, o desempenho de Alagoas também não foi satisfatório, entre todos os entes federados o Estado ficou em último lugar nas três áreas pesquisadas pelo programa: Ciências, Leitura e Matemática. Os alunos atingiram 342 pontos na prova de matemática, 355 pontos na prova de leitura e 346 pontos na prova de ciências, bem abaixo da média do país que é de 410 em leitura, 405 em ciências e 391 em matemática.

Outro importante dado é referente à redução no número de alunos matriculados na rede estadual de ensino em 2014. Segundo o Ministério da Educação, neste ano, 163.771 alunos realizaram suas matrículas nas escolas de zona urbana e 9.110 alunos nas escolas da zona rural, o que totaliza 172.881 alunos. Já no ano de 2013, 197.088 alunos se matricularam nas escolas urbanas do Estado, enquanto 10.018 alunos fizeram suas matrículas nas escolas rurais, totalizando 207.106 matriculados em toda a rede estadual.

Os resultados do Índice de Desenvolvimento da Educação Básica - Ideb - confirmam a situação em que se encontra o Estado de Alagoas. Este indicador, que mede a qualidade do ensino nos estados e municípios, apontou que a rede estadual de Alagoas, 
em 2013, ano do último resultado deste índice, teve a segunda pior nota $(3,7)$ dentre os alunos do $5^{\circ}$ ano, a pior nota $(2,7)$, junto com Sergipe, dentre os alunos do $9^{\circ}$ ano e a pior nota $(2,6)$ dentre os alunos do $3^{\circ}$ ano do Ensino Médio.

No tocante aos professores o Estado aplica a Lei Nacional do Piso do Magistério, lei n. $11.738 / 08)$, que define em $R \$ 1.917,78$ o vencimento inicial das carreiras do magistério público e define em 2/3 da carga horária o limite para horas-aula:

$\S 1^{\circ} \mathrm{O}$ piso salarial profissional nacional é o valor abaixo do qual a União, os Estados, o Distrito Federal e os Municípios não poderão fixar o vencimento inicial das Carreiras do magistério público da educação básica, para a jornada de, no máximo, 40 (quarenta) horas semanais.

$\S 4^{\circ} \mathrm{Na}$ composição da jornada de trabalho, observar-se-á o limite máximo de 2/3 (dois terços) da carga horária para o desempenho das atividades de interação com os educandos. (Brasil, 2008, artigo $2^{\circ}$ ).

A gestão democrática não é só um princípio pedagógico, mas também um preceito constitucional, dessa forma, a constituição Federal de 1988, no artigo 206, inciso VI, determina como um dos princípios basilares pelos quais o ensino será ministrado, a gestão democrática do ensino público (Brasil, 2006). O Estado de Alagoas, baseado neste princípio, determinou, pela lei n. 6.661 , de 28 de dezembro de 2005, a criação dos conselhos escolares, sob a forma de sociedade civil, nas unidades de educação básica da rede estadual de ensino, de modo que estes conselhos funcionem como instrumentos de facilitação no processo coletivo de integração da sociedade na administração, fiscalização e execução das ações e práticas educacionais.

Desse modo, com a obrigatoriedade deste princípio de gestão democrática na escola, surgiu a necessidade da mudança da forma como ela é vista, ou seja, sua concepção, bem como de sua gestão, já que toda a comunidade escolar se torna partícipe deste processo de gerenciamento da escola e suas práticas educacionais (Veiga, 2001).

Em Alagoas essa mudança de concepção aconteceu de forma lenta, gradual e com algumas falhas e distorções, pois, muitos dos atuais gestores ainda não compreenderam muito bem essa dinâmica, que exige trabalho de forma coletiva, principalmente no tocante as tomadas de decisões. Diógenes (2009, p. 5), aponta algumas situações sobre essa condição:

[pela] pesquisa, temos observado que são recorrentes determinadas práticas nos diversos estabelecimentos de ensino, como: gestores utilizando-se do mecanismo democrático, a eleição, para legitimar decisões autocráticas; gestores que abrem mão de posturas consideradas eticamente corretas do pondo de vista da administração pública por medo da perda do "status" ou de ser destituído de sua "zona de conforto"; gestores que se utilizam da fragilidade dos integrantes dos conselhos ou unidades executoras para ratificar atitudes de improbidades administrativas; gestores que se utilizam do patrimonialismo nas decisões do coletivo; gestores que atuam em moldes do tipo de um neo-coronelismo no espaço escolar e por aí vai.

Dentre estas práticas não democráticas, mesmo com a implantação e obrigatoriedade da gestão democrática, ainda observa-se que o pleito para o cargo de diretor escolar em muito se assemelha com o pleito realizado para os cargos do poder 
executivo e legislativo. Neste processo, que tem a democracia em sua essência e possui um eleitorado reduzido e específico, há compra de votos, alianças políticas, acordos pessoais.

Para que os profissionais da educação presentes na escola compreendam este novo paradigma de atuação e a importância de uma escola democrática e autônoma, é preciso esclarecer as competências que cada membro deve assumir, respeitando a existência de funções e níveis diferenciados na escola, pois todos devem ter espaço de participação (Cordeiro; Sousa; Rocha, 2009). Este é um dos objetivos do CFCE, tendo os profissionais nele envolvidos um importante papel na implantação da gestão democrática em Alagoas.

\section{O trabalho de conclusão do curso: da teoria à prática}

A gestão administrativa e pedagógica, com a atuação de órgãos colegiados não tem, na maioria das escolas das redes públicas de ensino, um tratamento específico, uma vez que apenas se adapta ao previamente estabelecido pelas políticas públicas de educação. Nesse sentido, ao depararmos com as análises de projetos de intervenção de vários técnicos de secretarias municipais e estadual de educação no curso de formação continuada em conselhos escolares, propusermos a investigar como ocorre a articulação entre o entendimento da participação dos órgãos colegiados para a garantia de ações democráticas na esfera educacional.

Os procedimentos previstos e utilizados para avaliação dos cursistas e suas formas de avaliação foram pautadas em reunião mensal com a coordenação e supervisão do curso, uma vez que entendiam ser o momento de dialogar com os formadores e tutores sobre as particularidades de cada turma. A equipe de trabalho - coordenação, supervisão, formadores e tutores - deixava claro que a formação continuada em conselhos escolares colabora para a compreensão das atribuições e os meios nos quais a atuação dos conselheiros pode cooperar para a melhoria da qualidade da educação nas unidades de ensino em Alagoas.

A organização das atividades relacionadas aos cursistas, especialmente para dar início e desenvolvimento no curso, foram propostas por meio de um modelo de plano tutorial diversificado, além de consentir ao grupo a possibilidade de refletir sobre as ações metodológicas para o ensino da coleção temática dos conselhos escolares que compõem doze volumes.

Alguns dos objetivos dos módulos neste curso de formação continuada em conselho escolar teve, como essência, formar técnicos das secretarias de educação estadual e municipal para que garantisse:

1) compreender como os integrantes do conselho escolar podem promover atuações de forma democrática em suas funções e práticas, com vistas a fortalecer a democratização da escola e a construção da cidadania;

2) entender a escola como prática social que visa ao desenvolvimento de cidadãos conscientes, autônomos e emancipados. Nesta compreensão a participação dos conselheiros se associa ao mecanismo de gestão democrática e de acompanhamento responsável da prática educativa, visando a sua função político-pedagógica e de transparência nas ações colegiadas;

3) compreender o papel do conselho escolar no acompanhamento das atividades na escola, especialmente com relação ao aproveitamento do tempo pedagógico; 
4) analisar os desafios, limites e possibilidades da gestão democrática e, a partir desse exercício analítico, refletir sobre a importância do fortalecimento dos mecanismos de democratização da escola, em especial do conselho escolar e dos processos de escolha dos diretores;

5) repensar os processos de decisão e deliberação, a organização e as condições de trabalho, os objetivos e as propriedades da instituição, a autonomia e a identidade escolar, o papel dos diferentes atores sociais, bem como as estratégias para a implantação de processos coletivos de decisão, especialmente do conselho escolar;

6) discutir o financiamento da educação básica no Brasil e contribuir com os conselheiros escolares na análise e compreensão das questões referentes a questão do financiamento no âmbito legal, o papel dos movimentos e órgãos colegiados na garantia do direito à educação;

7) contribuir para que o conselho escolar possa atuar como um dos instrumentos de gestão democrática nas escolas do campo.

O plano de tutoria instituía ajustes pedagógicos para dinamizar os conteúdos aos cursistas, uma vez que para se alcançar tais objetivos outros aspectos metodológicos como fórum, espaço tira dúvidas e tarefa final foram conduzindo os trabalhos. Tudo isso seguido por um cronograma de atividades ao longo de cada módulo que, posteriormente, culminava na avaliação do cursista e sua continuidade no curso.

Várias foram as formas metodológicas para o preparo do ensino no ambiente Moodle/Ufal pelos formadores e tutores. Uma delas, por exemplo, se configurava na participação por meio de fóruns. Nesta interação deveríamos formular questões para que estabelecesse um diálogo na participação entre os cursistas. A primeira participação acontecia pela respostas a uma questão formulada com a leitura dos cadernos. Já a segunda, com a mediação do formador e tutor e contextualização do material didático, era formulada diante da necessidade de aprofundar a temática.

As tarefas finais em cada módulo estavam baseadas na leitura dos cadernos do curso e na entrega de uma produção textual como o objetivo de responder a uma questão central contextualizada nas funções e nas práticas vivenciadas pelos técnicos que formam os conselheiros escolares nas unidades de ensino de seus municípios.

O critérios de avaliação da produção textual pautavam-se por uma redação entre 15 e 20 linhas pelos aspectos da importância de avaliar a prática administrativa, pedagógica e financeira do conselho na escola e a atuação dos conselheiros na construção coletiva de propostas para intervenção na escola. Concluía-se com o envio obrigatório do texto escrito pela plataforma Moodle/Ufal aos respectivos formadores e tutores.

Valorizava-se a existência de espaços de participação, de escuta e reflexão sobre a prática no âmbito de cada caderno proposto pelo MEC. Foram momentos de ouvir o outro, de idealizar novas formas de ensinar nesta modalidade educacional e de aprendizagem, que é fundamental para se perceber o quanto a qualidade educacional pode contribuir para a mudança nos espaços escolares e da implantação da gestão democrática no cotidiano escolar.

Diante do exposto conseguimos, com êxito, expressar a proposta do curso quando enxergamos que as realizações em cada cidade, por meio dos projetos de intervenção, foram as formas de se aplicar toda a aprendizagem na concretização das mudanças que somente por este curso se permitiria conjecturar. 
Os direcionamentos para o plano de intervenção adotavam as seguintes orientações: discutir a importância e o sentido de momentos fortes de formação, apresentando a fundamentação e o processo para contribuir com as atividades do conselho escolar. Na primeira parte discutiu-se a participação e a contribuição do conselho escolar no trabalho educativo vinculado com o movimento de construção da democracia e cidadania; apresentou-se bases e exigências da formação e sugeriu-se o círculo de cultura como forma de trabalho pedagógico na formação dos conselheiros e de outros grupos interessados em impulsionar seu processo de formação.

Assim, detalhando aspectos do círculo de cultura como metodologia de construção participativa do saber e da cultura e como metodologia importante no processo de formação, sugeriu-se uma forma de trabalhar na preparação e realização das reuniões de formação. Nesta segunda parte foram apresentadas sugestões e procedimentos para investigar uma situação-problema em cada município; estudar a situação e buscar alternativas e elaborar uma proposta de intervenção para programar a ação a ser desenvolvida.

Partindo da possibilidade de analisar as propostas dos projetos de intervenção apresentados por alguns cursistas, podemos ponderar, diante das problemáticas apresentadas, considerações que nos permitem afirmar a existência de um hiato entre a realidade nos municípios e o que é estabelecido pela Constituição Federal concernente a democracia no âmbito educacional. A Constituição Federal instituiu a gestão democrática do ensino público como forma própria de governar as escolas e os sistemas de ensino, regulamentado pela LDB.

Sendo assim, conseguimos constatar que nos projetos de intervenções as ideias centrais, em muitos casos, pautavam-se pela falta de formação e na dificuldade de atuação dos conselhos escolares. Segundo alguns técnicos dos municípios, uma das problemáticas para se conceber a gestão democrática era a efetivação de sua prática no cotidiano escolar.

Ao analisar os projetos de intervenção percebemos que os técnicos demonstraram vivenciarem uma experiência nova em alguns municípios, pois estavam experimentando o primeiro mandato dos gestores escolares com duração de dois anos. Logo, fez-se necessário a reformulação dos projetos político-pedagógicos das unidades escolares. Propuseram, também, cumprir com a instituição da eleição para o primeiro mandato dos conselheiros, portanto, acreditavam ser este o melhor e mais indicado momento para os conselhos escolares tomarem suas posições e juntos, escola e comunidade.

Este momento, de avaliar o trabalho executado, decidir o melhor caminho a ser seguido e planejar as ações a serem desenvolvidas pela escola para os próximos anos, seria para os técnicos a possibilidade da efetivação da gestão democrática. De acordo com a problemática apresentada houve relatos no sentido de ser possível solucionar questões de apadrinhamentos políticos e conchavos entre diretores e coordenadores pedagógicos. Segundo Veiga (1995, p. 18), “a participação democrática implica principalmente o repensar da estrutura de poder da escola, tendo em vista sua socialização". 
Sendo assim, além de transparecer que ainda há o engessamento da gestão democrática em cidades alagoanas, a participação na gestão escolar pode assumir o comprometimento em relação à qualidade da educação. E de forma significativa, o papel do gestor pode estabelecer ligações entre segmentos escolares e instâncias colegiadas, uma vez que

a socialização do poder propicia a prática da participação coletiva, que atenua o individualismo; da reciprocidade, que elimina a exploração; da solidariedade, que supera a opressão; da autonomia, que anula a dependência de órgãos intermediários que elaboram políticas educacionais das quais a escola é mera executora. (Veiga, 1995, p. 18)

Para muitos técnicos das secretarias de educação nas redes municipais e estadual, o conselho escolar é "uma das instâncias colegiadas de gestão na escola pública", (Plano de Ação, 2015). No entanto, segundos eles, "há muita dificuldade para o funcionamento adequado desse órgão colegiado, que por vezes, apresenta-se como mais um instrumento burocrático dentro da escola. Deixando, as vezes, de exercer muitas das atividades que Ihe são pertinentes" (Plano de Ação, 2015).

Percebemos, nos projetos de intervenção analisados, o que acreditam ser os órgãos colegiados, especificamente, o conselho escolar:

Ser conselho escolar o órgão máximo de gestão na escola pública, sendo inclusive indispensável um estudo mais aprofundado a respeito de suas atribuições e a sua relevância para a tomada de decisões no que tange aos dados de parâmetros e indicadores de qualidade na educação. (Projeto de intervenção, 2014, p. 2)

Ou seja, há a compreensão de que a qualidade precisa ser considerada como processual, coletiva, democrática, além de atingir todas as instituições educacionais e instâncias, respeitando individualidades, peculiaridades e especificidades.

É importante destacar que, nos projetos de intervenção, os técnicos levam em conta que os conselhos escolares podem exercer uma função especial no processo da qualidade da educação nas escolas, trazendo a oportunidade de discussão, de análise e de proposição para ações específicas da rede pública. Sabe-se que este é um importante mecanismo para refletir vulnerabilidades, problemas, potencialidades e repercussões não só da prática pedagógica, mas de todo o contexto educacional, redimensionando ações, instaurando melhorias e até mesmo adequando currículos.

Consequentemente, a gestão democrática não se simplifica apenas em decisões a respeito de aspectos e ações secundárias da unidade escolar. Necessita envolver análises das dificuldades e sucessos em busca de soluções coletivas. Segundo Vieira (2002, p. 27),

para a escola pública, tais reflexões representam uma oportunidade para reconhecer que as mudanças necessárias no sistema educacional são urgentes e demandam esforço coletivo de todos que fazem educação (profissionais, governos e sindicatos), assim como da sociedade como um todo. 
Portanto, vale ressaltar que, de acordo com Vieira (2006, p. 29) "a Constituição Federal define a educação como um direito de todos e dever do Estado e da família, a ser promovida e incentivada com a colaboração da sociedade", pois "a finalidade da educação é o pleno desenvolvimento da pessoa, seu preparo para o exercício da cidadania e sua qualificação para o trabalho" (CF, art. 205 e LDB, art. 2), pois a ampliação desta perspectiva parte de uma atitude democrática e coletiva. Enfim, nesse sentido alicerça a autonomia escolar. Pode ser esta uma forma de desenvolvermos, nos sujeitos inseridos em comunidade ou no âmbito escolar, a identidade da participação nas tomadas de decisão e na cultura da organização escolar.

\section{Considerações finais}

Embora com muitos problemas, não restam dúvidas de que a experiência da primeira turma do Curso de Extensão a Distância Formação Continuada em Conselhos Escolares em Alagoas trouxe várias contribuições para o fortalecimento da gestão democrática: permitiu que técnicos das secretarias de educação tivessem acesso a um curso gratuito de extensão universitária certificado pela Universidade Federal de Alagoas; possibilitou a definição de ações de forma coletiva, bem como a publicidade de todas as dificuldades do curso nos espaços coletivos do Centro de Educação da Universidade Federal de Alagoas; identificou o compromisso ético e profissional de vários docentes que assumiram os desafios propostos ao longo do curso.

Por fim, embora com objetivos importantes e altos investimentos financeiros, o curso não foi capaz de atingir as metas traçadas pelo MEC. Tal reconhecimento é fundamental para que ações sejam pensadas com vistas à reformulação do curso.

Desta forma, diante das limitações do presente texto, vários aspectos, não menos importantes dos que aqui foram apresentados, deixaram de ser discutidos, reforçando a necessidade de que mais estudos sejam produzidos sobre a temática, com especial destaque para os estudos que se proponham analisar a relação do curso com mudanças efetivas na gestão sob a participação ativa dos conselhos escolares.

\section{Referências}

ANDRADE, Everaldo Moreira. O tutor presencial na educação à distância: dimensões funções que fundamentam sua prática de tutorial. Curitiba: Universidade Tuiuti do Paraná, 2012. 70f. Dissertação (mestrado em educação). Universidade Tuiuti do Paraná.

BRASIL. Constituição Federal de 1988. Brasília: Senado Federal, 1988.

BRASIL. Lei n. 9.394, de 20 de dezembro de 1996 - estabelece as diretrizes e bases da educação nacional. Brasília, 1996.

BRASIL. Lei 11.738, de 16 de julho de 2008 - regulamenta a alínea "e" do inciso III do caput do art. 60 do Ato das disposições constitucionais transitórias, para instituir o piso salarial profissional nacional para os profissionais do magistério público da educação básica. Brasília, 2008.

BRASIL. Resolução CEB n. 2/1998. Institui as diretrizes curriculares nacionais para o ensino fundamental. Brasília: MEC, 1998. Disponível em <http://portal.mec.gov.br/cne/ arquivos/pdf/rceb02 98.pdf>. Acesso em 29 maio 2015. 
CORDEIRO, Edna Maria; SOUSA, Claudineia Ribeiro de; ROCHA, Jovina Benício Coelho. Gestão escolar: enfrentando os desafios cotidianos em escolas públicas. Campinas: CRV, 2009.

DIOGÉNES, Elione Maria Nogueira; CRUZ NETO, Tiago Leandro. Ética, cidadania e gestão democrática: paradoxos. São Luís: Universidade Federal do Maranhão, 2009.

DUARTE, Zalina Maria Cancela. Educação à distância (EAD): estudos dos fatores críticos de sucesso na gestão de cursos da região metropolitana de Belo Horizonte. Belo Horizonte: Fumec, 2011.

GADOTTI, Moacir. Gestão democrática com participação popular no planejamento e na organização do da educação nacional. 2014. Disponível em <http://conae2014. mec.gov.br/images/pdf/artigogadotti final.pdf>. Acesso em 26 maio 2015.

MACHADO, Liliana Dias; MACHADO, Elian de Castro. O papel da tutoria em ambientes de EAD. Fortaleza: Universidade Federal do Ceará, 2004.

SABATTINI, Renato Marcos Endrizzi. Ambiente de ensino e aprendizagem via internet: a plataforma Moodle. 2007. Disponível em <http://www.ead.edumed.org.br/file.php/1/ PlataformaMoodle.pdf>. Acesso em 26 maio 2015.

SOUZA, Carlos Alberto; SPANHOL, Fernando José; LIMAS, Jeane Cristina Oliveira; CASSOL, Marlei Pereira. Tutoria na educação a distância. Disponível em <http://www.abed.org.br/congresso2004/por/htm/088-TC-C2.htm>. Acesso em 26 maio 2015.

VEIGA, Ilma Passos Alencastro (org.). Projeto político-pedagógico da escola: uma construção possível. Campinas: Papirus, 1995.

VEIGA, IIma Passos Alencastro; RESENDE, Lucia Maria Gonçalves de. Escola: espaço do projeto político-pedagógico. Campinas: Papirus, 2001.

VIEIRA, Sofia Lerche; DAVIS, Claudia. Gestão da escola: desafios a enfrentar. Rio de Janeiro: DP\&A, 2002.

VIEIRA, Sofia Lerche; MEDEIROS, Isabel Letícia Pedroso de. Gestão escolar democrática: concepções e vivências. Porto Alegre: Ufrgs, 2006.

Javan Sami Araújo dos Santos é professor e atua na formação do Curso de Extensão em Conselhos Escolares MEC/Ufal.

Endereço: Avenida Cachoeira do Meirim, Benedito Bentes, 770, cond. Village das Fontes, bl. K, apto. 2 - 57084-700 - Maceió - AL - Brasil.

E-mail: javansami@hotmail.com.

Edna Cristina do Prado é professora na Universidade Federal de Alagoas, doutora em Educação Escolar pela Universidade Estadual Paulista Júlio de Mesquita Filho. Endereço: Endereço: Avenida Julio Marques Luz, 81/101 - 57035-700 - Maceió - AL - Brasil.

E-mail: wiledna@uol.com.br. 
Salatiel Braga Trajano Júnior é professor, atua como diretor de ensino e na formação do Curso de Extensão em Conselhos Escolares MEC/Ufal.

Endereço: Rua Francisco Leão, 380 - 57052-855 - Maceió - AL - Brasil.

E-mail: sbtrajanojr@hotmail.com.

Recebido em 14 de outubro de 2015.

Aceito em 30 de novembro de 2015. 